\title{
CASAIS DE MEIA-IDADE: ESTUDOS COM CASAIS PORTUGUESES NUMA PERSPECTIVA SISTÉMICA
}

\author{
Maria Teresa M. L. da Silveira Rodrigues Ribeiro ${ }^{1}$
}

Resumo: Neste trabalho, é abordado o tema dos casais de meia-idade numa perspectiva sistémica. Começa-se por caracterizar as tarefas evolutivas das mulheres e dos homens de meia-idade, aprofundando especialmente as mudanças que se verificam nas relações de conjugalidade, bem como a importância das relações intergeracionais. Partindo de resultados de investigação quantitativa e qualitativa com casais portugueses, ilustra-se, através da referência a estudos de caso, uma tipologia conjugal - tradicional, independente e ambivalente -, nesta fase do ciclo de vida (Fitzpatrick, 1989; Ribeiro, 2002). Apesar da diversidade dos casais e da sua consequente singularidade - cada casal é único e irrepetível -, é possível encontrar regularidades nas diferentes formas de viver a conjugalidade, designadamente na meia-idade.

Palavras-chave: casais de meia-idade, ciclo de vida familiar, tipologia conjugal, relações intergeracionais.

Midlife couples: Studies with portuguese couples in a systemic perspective (abstract): In this work we treat the theme of middle-aged couple in a systemic perspective. We start by characterizing the women and men evolutive tasks at that stage of the life cycle, studying in depth the changes in conjugal relationships and also in inter-generational relationships. Starting from data obtained from quantitative and qualitative research with Portuguese couples, we show, through cases studies, a marital typology - traditional, independent and ambivalent - at this stage of the life cycle (Fitzpatrick, 1989; Ribeiro, 2002). In spite of couples diversity and consequently, its singularity - each couple is unique and unrepeatable - it's possible to find regularities in different forms of living conjugality, namely at middle age.

\footnotetext{
${ }^{1}$ Professora Auxiliar da Faculdade de Psicologia e de Ciências da Educação da Universidade de Lisboa.
} 


\section{Introdução}

O que se convencionou designar por 'casais de meia-idade' assumiu, no final do século XX e princípio do século XXI, características diferentes das que se verificavam anteriormente. Com efeito, um conjunto de mudanças demográficas e socioculturais aparecem associadas a diversas alterações nas vivências privadas e públicas dos casais e famílias que se encontram naquela fase do ciclo de vida.

Duas grandes alterações demográficas - o aumento da esperança de vida e a redução do número de filhos - justificam que esta fase se tenha tornado a mais longa do ciclo de vida familiar, costumando decorrer, no que se refere à idade dos membros do casal, mais ou menos entre os $45 \mathrm{e}$ os 65 anos. Evidentemente que pode ser uma fase interrompida abruptamente pela morte precoce de um dos cônjuges ou pelo divórcio, como, pelo contrário, pode prolongar-se mais ou menos indefinidamente com filhos que tenham dificuldade em tornar-se independentes. É, também, caracterizada por ser a fase em que se verifica o maior número de saídas - filhos e de entradas - noras e/ou genros e netos - no sistema familiar.

Outras duas alterações demográficas verificadas na maioria dos países europeus conferem características particulares a esta fase comparativamente com o que se passava anteriormente no ciclo de vida das famílias. Trata-se, por um lado, do aumento de divórcios (INE, 2002b) ${ }^{2}$ e, por outro, do aumento do número de mulheres que trabalham fora de casa ${ }^{3}$. Com efeito, apesar da maior parte dos divórcios ocorrer nos primeiros tempos de casamento (Fisher, 1992), constata-se que também se verificam, com alguma frequência, nesta transição do ciclo de vida familiar. Surgem como alternativa a uma relação conjugal insatisfatória que, uma vez os filhos autónomos, não encontra razão para continuar e opta pelo divórcio. Este facto está, habitualmente, relacionado com a incapacidade por parte do

\footnotetext{
${ }^{2}$ Em Portugal, a média dos divórcios dos dois últimos anos continuou a aumentar, sendo que, cada vez mais, são por mútuo consentimento $(86,5 \%)$ e, cada vez menos, são litigiosos (13,2\%). Em ambos os sexos, entre 1992 e 2001, proporcionalmente há menos pessoas a divorciarem-se com menos de 30 anos. No que se refere à duração do casamento dissolvido por divórcio, a tendência é a de aumento de divórcios em casamentos recentes (dos 0 aos 4 anos) que passaram de 12,2\%, em 1992, para 18,3\%, em 2001. Os divórcios de casamentos com 25 anos ou mais anos aumentaram, passando de $13 \%$, em 1992, para 15,5\%, em 2001. O grupo dos 5 aos 9 anos de casamento continua Maioritário nos divórcios por duração de casamento, mas a sua importância relativa diminuiu de 25,1\% (1992) para 23,5\% (2001). Nos casais com filhos, a frequência dos divórcios vai diminuindo à medida que o número de filhos vai aumentando (INE, 2002b).

${ }^{3}$ Portugal é o único país da OCDE em que a percentagem de mães a trabalhar a tempo inteiro $(92 \%)$ é superior à das mulheres sem filhos, especialmente aquelas que detém baixa qualificação (Employment Outlook, 2002, OCDE).
} 
casal de reestruturar a sua relação após a saída dos filhos - teria sido um casal que se teria mantido unido ao longo dos anos, com o objectivo primordial de educar os filhos, sem aprofundar e enriquecer a sua relação conjugal. A outra alteração demográfica - o número crescente de mulheres a trabalhar fora de casa - não só muda a situação económica do casal desta fase do "ninho vazio", como vem tornar menos "vazia" esta fase para as mulheres. De facto, um dos motivos desta designação prendia-se, anteriormente, com o facto de as mulheres nesta fase do ciclo de vida deixarem de ter uma das suas tarefas principais - a educação dos filhos (Carter \& McGoldrick, 1989; McCullough \& Rutenberg, 1989).

Inerente à designação de casais de meia-idade estão os conceitos de tempo, processo e mudança, os quais são fundamentais para a compreensão da conjugalidade no que se refere às respectivas qualidade, estabilidade $\mathrm{e}$ funcionalidade (Heaton, 1991; Relvas, 1996). Não é um padrão linear de mudança, com passagens progressivas de uns estados para os outros, mas um padrão recorrente de mudança cíclica, com avanços e recuos, "um desenvolvimento circular evolutivo" (Pina Prata, 1994).

Diversos autores, conforme anteriormente referimos, designam esta fase do ciclo de vida das famílias como "ninho vazio" (McCullough \& Rutenberg, 1989; Carter \& McGoldrick, 1989), na medida em que se trata da fase em que os filhos vão sair de casa para viver independentes dos pais (constituindo ou não outras famílias) e o casal fica, de novo, só. Esta fase tem, habitualmente, o seu início com a saída do primeiro filho de casa e termina com a saída do último, o que, por vezes, coincide com a reforma dos pais. No entanto, denominar esta fase por "ninho vazio" confere-lhe um teor negativo que nem sempre corresponde à realidade. McCullough \& Rutenberg (1989) referem a ocorrência de expectativas diferentes relativamente a esta fase. Assim, enquanto para alguns casais será uma fase de descontracção e plenitude, uma segunda oportunidade para consolidar ou expandir novos caminhos e papéis; para outros significará um tempo de perturbação (conflitos, divórcio), um tempo de vazio (sem os filhos para preencher a vida), um tempo de decadência (doença, enfrentar as suas próprias limitações e a morte dos mais idosos).

Também está contemplada na designação de "casais de meia-idade" a situação de todos os casais que, não tendo filhos, mantém a relação conjugal nas idades que anteriormente referimos (a partir dos 45 anos até mais ou menos os 60/65 anos). Destacamos o modelo de Frank-Lynch (1986, citado por Relvas, 1996) que descreve o ciclo vital do casal em três está$\operatorname{dios}^{4}$, sendo que o terceiro - denominado empatia - corresponderia à situa-

\footnotetext{
${ }^{4}$ As outras fases são designadas pelo autor como estádio de fusão (correspondendo, globalmente, aos primeiros 10 anos de relação conjugal), em que ocorre a formação do
} 
ção dos casais de meia-idade, caracterizada por um novo reinvestimento na relação conjugal, no sentido do 'nós', aliado a um conjunto de mudanças físicas, psicológicas e sociais de cada um dos cônjuges.

Apesar de ser, habitualmente, uma fase marcada pelo fim de um dos grandes objectivos de qualquer sistema familiar - a educação, a protecção e socialização dos filhos até estes se tornarem independentes -, implica, também, um conjunto de transições familiares e de tarefas de desenvolvimento pessoal (biológicas, psicológicas e sociais), para além da função parental aqui bem expressa. Cada membro do casal e o sistema familiar como um todo vão ter que se reestruturar (Carter \& McGoldrick, 1989), criando novos padrões de relação e abandonando papéis e funções que se tornem desajustadas aos desafios da nova fase. Trata-se de perceber e de corresponder aos novos desafios do casal pós-parental, uma outra fase da conjugalidade em que é necessário desenvolver as tarefas do casal de meia - idade, bem como desenvolver relações adulto/adulto entre pais e filhos, expandir as relações familiares, de modo a incluir noras/genros e netos, cuidar da geração mais idosa, desenvolver relações intergeracionais (Ribeiro, 1996).

Como facilmente se deduz, trata-se de uma fase que envolve todo o sistema familiar nas relações particulares intra e intergerações. O próprio sentido de família será testado a vários níveis. No que se refere à conjugalidade, uma vez que, se não se foi cuidando a relação conjugal ao longo dos anos, o casal dificilmente se adaptará a uma vida em que a função parental deixou de ser significativa na organização da relação. No que concerne aos filhos que saem de casa e constituem, mais cedo ou mais tarde, as suas famílias nucleares, podem ter estilos de vida que dificultem a relação com os pais, como também podem dar sentido de continuidade entre gerações, ao começar a dar netos à família. No que diz respeito à geração mais idosa a entrar no fim da vida, vai exigir mais atenção e cuidados e colocar o dilema, entre outros, da assistência em casa ou em instituição. Para além disto, é uma fase em que se desempenham uma diversidade de papéis: marido/mulher; pai/mãe; sogro/sogra; avô/avó; filho/filha de pais idosos. Zal (1992) designa-os por "geração sanduíche" porque estão entre filhos (adolescentes e jovens adultos) e pais idosos, ambos a exigir apoio diferenciado da geração do meio.

'nós', o que implica um grande investimento na relação e a procura de reequilíbrios nas relações com outros sistemas, como a rede social, famílias de origem; e estádio de retorno ao 'tu' e ao ' $e u$ ' (correspondendo, no geral, ao tempo entre os 10 e os 20 anos de casamento), em que se observa uma maior consciência e análise individual e da relação e a tendência para um retorno ao investimento na autonomia e individualidade, o que pode aumentar as ideias de ruptura e/ou receio de ruptura. 
Evidentemente que a forma mais funcional ou mais disfuncional como decorrerá a transição para esta nova fase depende, em parte, da forma como o sistema familiar viveu as transições familiares anteriores (Ribeiro, 1991).

Vamos começar por caracterizar muito brevemente ${ }^{5}$ as tarefas de desenvolvimento que se colocam à mulher e ao homem que entraram na fase de meia-idade, focando as suas particularidades biológicas, psicológicas e sociais. Depois, vamos reflectir sobre as mudanças na conjugalidade que se verificam nesta fase e vamos delinear as principais tarefas evolutivas que se colocam ao casal de meia-idade, destacando o seu papel fundamental nas relações entre gerações. Finalmente, apoiados em dados de investigação com casais portugueses (Ribeiro, 2002), reflectiremos sobre três estudos de caso ilustrativos, respectivamente, de três formas diferentes de viver a conjugalidade nesta fase do ciclo de vida, de acordo com a tipologia de Fitzpatrick (Fitzpatrick, 1988; Fitzpatrick, Fey, Segrin, \& Schiff, 1993; Ribeiro, 2002).

\section{Tarefas evolutivas da mulher "pós-maternal"}

As mulheres que entram na fase denominada de "ninho vazio" deparam-se com um conjunto diversificado de tarefas de desenvolvimento. Em primeiro lugar, surge a forma muito pessoal como irá ser vivida esta fase (relacionada com o estilo idiossincrático de vida ao longo dos cerca de 40/45 anos já passados) e que será diferente de mulher para mulher. Para além disso, estas tarefas têm uma base biológica importante, na medida em que a mulher está a entrar na menopausa, e uma base sociocultural referente às expectativas e pressões da sociedade.

De um modo geral, as tarefas evolutivas são as seguintes: manter um estado saudável; facilitar a autonomia dos jovens adultos (filhas e filhos); prosseguir (ou iniciar ou mudar) os interesses profissionais; manter uma vida social satisfatória e desenvolver responsabilidades na comunidade.

\section{Manter um estado saudável}

Biologicamente, a menopausa (fim da função dos ovários e cessação da menstruação) marca a entrada da mulher num estado que durará até ao fim da sua vida. É o final do ciclo reprodutivo provocado por alterações hormonais (diminuição dos estrogénios e aumento da hormona luteinizante e de gonadotrofina) e, frequentemente, está associado à manifestação de

\footnotetext{
5 Trata-se de uma caracterização breve, uma vez que este tema é objecto de outros artigos da presente revista.
} 
sintomas físicos como acessos de calor, suores, palpitações, enxaquecas e, às vezes, a sintomas emocionais, tais como excitabilidade, fadiga, ansiedade, sentimentos de inutilidade (Zal, 1992). Trata-se de reencontrar um novo equilíbrio físico numa mudança de vida que alguns estudiosos afirmam ter mais efeitos sociais que fisiológicos, correspondendo à forma enraizada como se encara o envelhecimento nas sociedades ocidentais (Townsend \& Carbone, 1980).

De qualquer modo, o que está em causa é o desempenho de uma tarefa relacionada com mudanças físicas inevitáveis - alterações na pele, cabelo, peso, nível de energia. O que é desejável é que a mulher se adapte e integre estas mudanças num estilo saudável (exercício físico, dieta equilibrada) e muito próprio. O estado de bem-estar é visível no arranjo pessoal geral, na forma como procura agradar a si própria e aos outros. Frequentemente descobrem que esta fase tem um "charme" muito próprio, o "sabor" da maturidade e o tempo e disponibilidade mental para fazer coisas de que sempre gostaram, desenvolvendo interesses novos que mantenham a sua vitalidade.

\section{Facilitar a autonomia dos jovens adultos (filhas e filhos)}

Apesar de cada vez mais mulheres terem a sua profissão e das tarefas domésticas, bem como a educação dos filhos, tenderem a ser mais repartidas entre marido e mulher, não há dúvidas de que é, ainda, a mulher quem acaba por concentrar grande parte da sua energia na atenção e cuidado dos filhos (Hiller \& Philiber, 1988). Por isso, quando os filhos saem de casa e ela continua a exercer a sua profissão, é natural que experimente sentimentos contraditórios. Por um lado, sente-se mais livre, uma vez que fica aliviada da dupla exigência da família e do trabalho; por outro lado, necesasriamente, sentirá um "vazio" no respeitante às suas preocupações maternais.

Assim, esta tarefa evolutiva consistirá em conseguir libertar-se da necessidade emocional de "ser indispensável" aos filhos e em facilitar o processo de saída dos filhos no caminho da autonomia e do estabelecimento de uma relação (com eles) de adulto para adulto. É um processo de aprendizagem em que se pode e deve incrementar o apoio mútuo, mas sem intromissão na vida uns dos outros, nem atenção excessiva à vida independente dos filhos. Para a mãe que foi trabalhando o "leaving home" progressivo dos filhos, no sentido de lhes ir gradualmente facultando a tomada de decisões e responsabilidades, esta tarefa é desempenhada com naturalidade.

As mulheres que são bem-sucedidas nesta tarefa, e que, portanto, ficam "livres da necessidade consumista de serem necessitadas pelos filhos" (Duvall, 1977, p. 358), conseguem relacionar-se com os filhos, respeitando 
e promovendo a sua independência, e aceitar com mais facilidade as noras e/ou genros, bem como os netos.

\section{Prosseguir (ou iniciar ou mudar) os interesses profissionais}

Como já foi referido anteriormente, a maior parte das mulheres actualmente trabalha quando se dá a entrada na fase de "ninho vazio". Constitui tarefa de desenvolvimento o facto de procurar desenvolver com competência e criatividade a sua profissão, tentando progredir na carreira. É muito recompensador o sentimento de ser produtiva e de progredir através das capacidades e daquilo que Duvall (1977) designa por "sabedoria amadurecida".

Para algumas mulheres, coincide o facto de os filhos saírem de casa com o início da sua profissão ou com uma mudança de profissão. Podem sentir dificuldade em só começar nesta altura, vivendo com desagrado a competição no trabalho, como podem, também, iniciar nesse momento uma carreira brilhante. Algumas mulheres dedicam o tempo livre deixado pela ausência dos filhos a ajudar o marido na sua profissão ou passam a encarregar-se de tarefas anteriormente a cargo dos maridos (por exemplo, o planeamento financeiro do casal). Felizmente, existem diversos cursos de educação de adultos e extensões universitárias que podem ajudar as mulheres a actualizarem os seus conhecimentos e a desenvolverem novas competências.

Tudo isto são formas de desempenhar a tarefa de desenvolvimento que é a de manter activos os interesses profissionais. Há mulheres que não o conseguem e que, portanto, vivenciam com desagrado e sentimento de vazio o facto de os filhos terem saído de casa. Têm dificuldade em saber como preencher o tempo que lhes passou a sobrar. Estudos realizados demonstram que as mulheres com carreira profissional referem, habitualmente, graus mais elevados de satisfação com a vida do que aquelas que foram donas-de-casa todo o tempo (Steil, 1997).

Uma forma encontrada por diversas mulheres para desempenhar esta tarefa evolutiva consiste em desenvolver actividade criativa nas artes, literatura, escrita, música, desporto ou trabalho voluntário. Deste modo, sentem-se ocupadas e vão preenchendo a vida de uma forma que não é contingente a recompensas monetárias.

\section{Manter uma vida social satisfatória e desenvolver responsabilidades na comunidade}

Esta tarefa de desenvolvimento consiste não só em corresponder às solicitações sociais que forem surgindo como em tomar a iniciativa de, também, as promover. As mulheres que vivem com apatia e desinteresse 
esta fase da vida isolam-se com frequência e, facilmente, se deprimem. Há, no entanto, outras mulheres que, nesta fase pós-parental, sentindo-se mais livres para usar o tempo de lazer, de acordo com os seus interesses, apuram a arte de fazer amizades, mantendo-se em contacto com velhos amigos e cultivando novos interesses e amizades. Às vezes aderem a organizações como, por exemplo, clubes de mulheres ou grupos sociais ligados à sua profissão. Convém relembrar que, habitualmente, são as mulheres as "especialistas" de relações familiares. São elas quem, na maior parte dos casos, mantêm os contactos através de telefonemas, cartas, visitas, lembranças e celebrações de acontecimentos especiais. É esperado, culturalmente, que nesta fase continuem a desempenhar essa tarefa fundamental.

Também se insere, aqui, a participação mais ou menos activa da mulher na comunidade em que está inserida. Referimo-nos a diversas actividades, desde as ligadas à igreja, a entidades de cariz social e caritativo, a grupos culturais ou a grupos políticos locais. $\mathrm{Na}$ área do envolvimento cívico, encontramos diferenças consoante o grupo social de pertença. Assim, verifica-se que as mulheres de classe social média e elevada estão mais sensibilizadas para este tipo de questões do que as que pertencem a uma classe mais baixa, a não ser que isso possa afectar o trabalho do marido ou a vida dos filhos e netos.

\section{Tarefas evolutivas do homem "pós-paternal”}

Durante esta fase, o desempenho das tarefas evolutivas pelo homem de meia-idade vai depender, também, de aspectos pessoais (biológicos e psicológicos) e socioculturais. Para além das tarefas que executará conjuntamente com a mulher e que referiremos posteriormente, o pai pós-paternal tem, pelo menos, as seguintes tarefas de desenvolvimento pessoal: manter um estado saudável; prosseguir (ou manter) os interesses profissionais; manter uma vida social satisfatória e envolver-se comunitariamente.

\section{Manter um estado saudável}

No homem de meia-idade, característico desta fase, verificam-se diversas alterações físicas, no início do processo de envelhecimento. Não só se constata uma diminuição da resistência e da energia física, como se verificam mudanças menos evidentes, como é o caso da redução na secreção da hormona testicular. Isto não implica um consequente declínio sexual, nem redução do desejo e do prazer, apesar de se verificarem alterações na 
expressão da sexualidade. É bastante comum encontrar nos homens uma certa ansiedade emocional e cultural relativamente ao "ficar velho", quando começa a constatar as alterações no peso, no cabelo ou na resistência à fadiga. Tal como na mulher, podem observar-se sintomas físicos (por exemplo, úlceras, acidentes cardiovasculares, fadiga crónica) e/ou emocionais (por exemplo, depressão, desilusão, baixa auto-estima).

Estes sintomas, caso sejam reconhecidos e compreendidos, podem, segundo Zal (1992, p. 108), ser muito úteis como alerta para o homem de meia-idade "adoptar novos padrões de vida, mais criativos, produtivos e satisfatórios". Desempenhar correctamente esta tarefa evolutiva passa, por isso, pelo cuidar da sua forma e aparência física, nomeadamente através de exercício regular e dieta equilibrada e por aproveitar todas as oportunidades da vida para se desenvolver em maturidade e "sabedoria".

\section{Prosseguir os interesses profissionais}

Dado que os homens não vêem ainda, tanto como as mulheres, o seu tempo dividido entre tempo para o trabalho e tempo para a família, é-lhes mais fácil encontrar continuidade ou ascensão no que se refere à carreira profissional, durante esta fase. Evidentemente que sentem o impacto da saída dos filhos de casa, mas raramente como a mulher cujo emprego é mais facilmente secundarizado face à tarefa de educação dos filhos. É-lhes, provavelmente, até mais fácil encorajar a autonomia dos filhos.

Habitualmente, nesta fase, muitos homens atingiram o topo da sua carreira. Podem sentir satisfação, orgulho, ter uma boa auto-imagem da sua competência e continuar o esforço para a manter e melhorar no futuro. Podem, também, entender que foram o mais longe que lhes era possível e tentar uma segunda carreira que os consiga preencher em áreas não contempladas na anterior carreira profissional, nomeadamente em criatividade e desafio. Também se verifica, por vezes, um certo desalento e frustração face à "obra feita", sobretudo quando comparada com os planos e intenções do início da carreira profissional.

Torna-se fundamental para um bom desempenho desta tarefa o sentir-se útil e competente no trabalho, para poder competir com os mais novos. A forma de manter vivos os interesses profissionais passará, necessariamente, por fazer valer junto dos outros o seu "saber-fazer" feito de experiência, maturidade e abertura à novidade. Um fenómeno com que as sociedades contemporâneas mais desenvolvidas têm que lidar é com a existência de reformas antecipadas. Para alguns homens isso é vivido com frustração e depressão; para outros é vivido como libertação e, tendo recursos para tal, como oportunidade de canalizar os seus interesses para outras áreas laborais ou não. 


\section{Manter uma vida social satisfatória e envolver-se comunitariamente}

Tal como acontece com a mulher, o homem/pai pós-paternal tem mais tempo livre nesta fase do ciclo de vida familiar. Não só tem mais tempo como tem, também, mais recursos económicos que, anteriormente, eram canalizados, na sua maioria, para a educação dos filhos e sustento da casa. Encontram-se homens que, nesta fase, mudam o tipo de actividades, por exemplo, gastando menos tempo em actividades de equipa, em benefício de actividades como golfe, pesca, natação, leitura, jardinagem, viagens - tudo actividades susceptíveis de ser mantidas individualmente e ao longo dos anos. A maior parte das responsabilidades de cidadania são assumidas por pessoas nesta fase da vida, sobretudo os homens, não só porque têm mais tempo disponível, como são áreas do seu interesse e preocupação, têm mais poder de influência e possibilidades de liderança.

Este tempo livre também pode ser gasto em apatia, desalento, alienação televisiva. Para Duvall (1977, p. 364), um homem é sábio se "equilibrar interesses de lazer sedentários com outros mais activos, apreciar quer as horas solitárias quer as sociais...". Com alguma frequência se assiste a um aumento do tempo que o casal passa em actividades conjuntas de lazer.

\section{Tarefas evolutivas do casal de meia-idade}

\section{Mudança de funções do casamento e desenvolvimento de tarefas do casal de meia-idade}

$\mathrm{O}$ casal que se manteve junto ao longo das diferentes fases do ciclo de vida familiar, desde o seu início, vai encontrar diferenças significativas na sua relação conjugal. Isto sentir-se-á, com maior ou menor premência, consoante o casal tenha ou não aprofundado e enriquecido a sua relação conjugal ao longo dos anos e tenha ou não acompanhado de perto a evolução pessoal que, inevitavelmente, cada um dos cônjuges fará desde que se conheceram, namoraram, casaram, tiveram filhos e os criaram, promovendo a sua autonomia, até ao momento presente de casal de meia-idade. Para aqueles casais cuja força organizadora da sua relação esteve principalmente centrada na educação dos filhos, o reajustamento conjugal será mais acentuado nesta fase.

Os autores são unânimes em considerar que uma tarefa com que estes casais se deparam consiste em reencontrar um equilíbrio na sua relação. Isto passa por um certo "balanço" da relação a dois, uma redescoberta mútua, uma reconstrução da relação a dois, aferindo o projecto de vida conjunta que tinham e o que pretendem alcançar no futuro. De certa forma, 
exige uma reflexão sobre o sentido de família e, sobretudo, de conjugalidade.

Por vezes, o cônjuge é uma pessoa tão diferente daquela com quem se casou há cerca de trinta anos, que é difícil reencontrar pontes. Se não se foi construindo a relação de casal, ao longo dos anos, é muito provável que se acentue um afastamento entre os cônjuges que se pode manter num estilo de vidas distantes e paralelas com mínimos pontos de contacto, ou evoluir para situações de conflito crónico que podem conduzir ou não a uma situação de divórcio. Pelo contrário, os cônjuges que se foram acompanhando um ao outro nas respectivas evoluções pessoais e na relação a dois, podem chegar a esta fase e redescobrir com encanto renovado o prazer de estarem casados um com o outro. Podem até atingir, nesta fase do "ninho vazio", um nível bastante elevado de satisfação conjugal: redescobrem-se um ao outro com maturidade; têm um passado de vida conjunta que os une; e planos para o futuro que podem mais facilmente realizar, uma vez que não só têm mais tempo para estar juntos como estão mais livres das suas tarefas parentais (Narciso, 2001). Lauer e Lauer (1986), com uma amostra de 351 casais com 15 anos ou mais de casamento, estudaram as razões de manutenção do casamento. Nos casamentos em que havia satisfação, os cônjuges consideravam-se os melhores amigos um do outro, gostavam do outro como pessoa, concordavam um com o outro nos objectivos a alcançar, estimulavam o humor, e evidenciavam formas construtivas de resolução de conflitos. Há casais que, no processo de redescoberta conjugal acima mencionado, remodelam a casa depois dos filhos terem saído de casa, adaptando-a às suas necessidades e gostos actuais.

É um facto que, na ausência dos filhos, a relação conjugal, independentemente da sua natureza, ganha relevo. Vamos assistir a um delineamento mais nítido das fronteiras (Minuchin, 1974) entre os dois subsistemas principais a que homem e mulher pertencem: o subsistema conjugal e o subsistema parental. É a consolidação do "nós" da relação conjugal a que se refere Caillé (1991) que vai ganhar proeminência. De acordo com McCullough e Rutenberg (1989), o afastamento dos papéis sexuais tradicionais que se verifica na fase pós-parental parece estar relacionado com a satisfação conjugal. Central na relação conjugal é o modo como se foram conjugando as necessidades de intimidade e de separação, como se foram processando as relações de interdependência. As situações extremas a evitar são ou a excessiva dependência de um dos cônjuges relativamente ao outro, ou o sentimento de "estar só no mundo" nas relações conjugais distantes (Swensen, Eskew, \& Kohlepp, 1981).

Se bem que a qualidade conjugal varie ao longo do ciclo de vida, os estudos realizados sobre a influência do tempo na satisfação conjugal não são conclusivos. Verifica-se, quando muito, alguma concordância na iden- 
tificação de um padrão curvilinear em que a qualidade conjugal se apresenta mais elevada nos primeiros anos de relação, seguida de um declínio que coincide com o crescimento e adolescência dos filhos e com os anos intermédios da relação, voltando a aumentar após a meia-idade (Dickson, 1997; Feeney, Noller, \& Ward, 1997; Glenn, 1990, 1998; Levenson, Carstensen, \& Gottman, 1994; Lupi \& Frideres, citado por Bahr, 1992; Suitor, 1991).

Os padrões de mudança identificados na satisfação conjugal parecem também variar consoante os métodos utilizados na investigação são transversais (padrão curvilinear) ou longitudinais (Feeney, Noller, \& Ward, 1997; Karney \& Bradburry, 1997; Vaillant \& Vaillant, 1993).

Diversos estudos demonstram que os filhos parecem afectar negativamente a interacção e a satisfação conjugal, se bem que à medida que crescem tal efeito negativo seja atenuado, transformando-se mesmo num efeito positivo (Lindahl, Malik, \& Bradbury, 1997; Zuo, 1992). Além do mais, mesmo quando os pais referem declínios na satisfação conjugal após o nascimento dos filhos, continuam a descrever os efeitos das crianças de um modo positivo (Sanders, Nicholson, \& Floyd, 1997). A existência de filhos também parece ter uma forte influência na estabilidade conjugal, dado que tendem a aumentar o compromisso (pessoal e/ou moral e/ou estrutural) conjugal e a diminuir o risco de divórcio (Belsky, 1990; Glenn, 1990; Lindahl, Malik, \& Bradbury, 1997; Sanders, Nicholson, \& Floyd, 1997).

Apesar da maior parte da investigação sobre conjugalidade incidir sobre casais mais jovens, alguns estudos realizados descrevem os casais na fases mais tardias do ciclo de vida como "felizes, afectiva e emocionalmente próximos" (Dickson, 1997; Levenson, Carstensen, \& Gottman, 1994; Narciso, 2002; Orbuch, House, Mero, \& Wester, 1996). A constatação da existência desta qualidade emocional positiva é consonante com a teoria segundo a qual, a partir da adultície e ao longo da vida, as pessoas vão limitando activamente o seu derredor social, aumentando a proximidade emocional e atribuindo maior importância às relações significativas. No entanto, outras investigações (Fletcher \& Thomas, 2000; Thomas, Fletcher, \& Lange, 1997) revelam que, à medida que a idade vai avançando, se verifica "uma diminuição da capacidade dos indivíduos para avaliar com precisão os estados cognitivos e afectivos dos seus parceiros durante a interacção conjugal quotidiana" (p. 839) como se, à medida que aumentasse o tempo de casamento, os casais se tornassem menos motivados para resolver os seus conflitos, rigidificando as suas 'teorias da relação' (Fletcher, 2002) e partindo do princípio de que saberiam sempre o que o outro estaria a pensar. Assim, esforçar-se-iam menos cognitivamente em situações interactivas de resolução de problemas e seriam menos capazes 
de detectar e utilizar adequadamente os sinais que permitem a avaliação dos estados cognitivos e afectivos.

Quando se verificam as características relacionais que aumentam habitualmente com o tempo de relação - a partilha de memórias, o conhecimento mútuo -, a intimidade conjugal é enriquecida (Glenn, 1998). À medida que os casais criam um mundo partilhado, onde as significações são integradas num todo coerente, a segurança na relação aumenta, uma vez que os acontecimentos passados são mais facilmente compreendidos e os futuros mais previsíveis (Fletcher, 2002).

Alguns estudos (McCullough \& Rutenberg, 1989) realizados com casais evidenciam uma relação entre o "manter-se casado com satisfação" e o grau de saúde física manifestado pelos cônjuges. Por outro lado, também foi encontrada relação significativa entre disfunção conjugal e os auto-registos de depressão por parte dos cônjuges, num estudo realizado por Pitman e Lloyd (1988) com casais em que um dos cônjuges manifestava sintomas de depressão.

Há casais para quem o entrar na meia-idade foi um processo gradual. Para outros, e muitas vezes comparando com a vida que os filhos adultos têm e o tipo de relações conjugais que constroem, é premente mudar e descobrir novas facetas da vida, como se o tempo urgisse. Estes sentimentos são bastante frequentes na meia-idade. Como afirma Darrell Sifford (citado por Zal, 1992, p. 105), faz parte do dilema da meia-idade "a dor importuna dos sonhos por realizar e o confronto angustiante com a realidade - encarar honestamente o fosso entre aquilo que pensámos que seriam as nossas vidas quando as planeámos e aquilo que agora sabemos que estas são de facto (...). Uma época em que começamos a ver a vida como ela é - cheia de altos e baixos".

Nos estudos que têm sido feitos sobre o perfil dos homens e das mulheres de meia-idade, há uma característica comum investigada, seguindo a tradição dos estudos de Erickson (1968) - o nível de maturidade alcançado. Bowen (1978) baseia a sua definição clássica de maturidade (que faz equivaler à diferenciação) no equilíbrio entre individuação e coesão. Isto tem significados diferentes para o homem e para a mulher. Para esta, dado o valor que atribui às relações e à união, mostrar maturidade estará relacionado com o conseguir aliar na intimidade alguma capacidade de autonomia e independência. Ou seja, é esperado das mulheres maduras que continuem como especialistas de relações na família e na sociedade, sem descuidar as suas necessidades pessoais, isto é, conjugando o "estar bem com os outros" e o "estar bem consigo própria". Facilmente se compreende que sejam as mulheres, por comparação com os homens, a sentir mais o impacto da saída dos filhos de casa e, por exemplo, a viver a inexistência de descendência como um grande handicap na sua vida. Se lhes for possí- 
vel continuar a cultivar relações com os filhos adultos, com netos e com amigos, então é com grande satisfação que vivem a fase de "ninho vazio". Este facto ainda se torna mais evidente quando a mulher já exercia uma actividade profissional anteriormente à saída dos filhos de casa, passando, com aquele facto, a poder dedicar mais tempo e energia à sua carreira profissional. Os homens, evidentemente, também vivem o impacto da saída de casa dos seus filhos. Podem senti-la como uma perda pessoal, pois também se implicaram (se bem que mais à distância) na educação dos filhos. Vê-los adultos activos, se bem que muito gratificante, também é, por vezes, vivido como sinal de que estão a entrar na recta final das suas vidas. Os objectivos de carreira profissional (promoções, reconhecimento da competência, sucesso financeiro) continuam muito activos nesta fase, como tivemos oportunidade de perceber umas páginas atrás. De um homem com maturidade é esperado que prossiga os seus interesses profissionais (investindo na mesma carreira ou mudando) e que os concilie com um maior investimento nas relações familiares e sociais, aliando o "estar bem consigo próprio" com o "estar bem com os outros".

Desenvolvimento de relações adulto/adulto entre os filhos crescidos e os seus pais

Considerar os filhos como adultos e interagir com eles enquanto tal é uma tarefa (nem sempre fácil) que se coloca ao casal de meia-idade, na fase de "ninho vazio". É o culminar de todo um processo de autonomia e socialização dos filhos que vai desde a infância ao estado de jovem adulto, passando pela adolescência. Está relacionado com a saída para a escola, com o modo como eram ou não estimuladas as relações com os amigos e com a sociedade em geral.

Admitir a independência dos filhos e relacionar-se positivamente com eles enquanto adultos depende, pois, bastante da forma como a família foi lidando, ao longo dos anos, com o processo de maturação e autonomia dos filhos. De acordo com Stierlin (1979), as famílias situar-se-iam num continuum cujos extremos seriam o funcionamento centrípeto e o funcionamento centrífugo. Segundo esta tipologia, as forças centrípetas da família operariam para impedir os filhos de sair de casa, enquanto as forças centrífugas impeliriam precocemente os filhos para fora do sistema familiar. Diversos estudos realizados, sobretudo no domínio da terapia familiar, permitem-nos concluir que quando as famílias têm dificuldade neste processo, é porque o subsistema filial desempenha uma função equilibrante de todo o sistema familiar que se encontra disfuncional (Haley, 1980; McGoldrick, 1989; Minuchin, 1974; Narciso, 2002; Ribeiro, 1994). 
O desenvolvimento de relações adultas com os filhos está bastante associado com a forma como se processou a relação dependência/independência nas respectivas famílias de origem e com o tipo de relação existente presentemente. Assim, extremos de relação, sejam eles de distanciamento ou de proximidade não parecem ter efeitos positivos no processo de independência da geração dos jovens adultos. De acordo com McCullough e Rutenberg (1989, p. 294), se um dos pais cortou emocionalmente com os seus pais viverá com demasiada intensidade a separação relativamente aos seus filhos. Do mesmo modo, um envolvimento excessivo com a geração idosa da família pode relacionar-se com respostas problemáticas nos próprios filhos.

Com efeito, os indicadores de uma separação bem-sucedida - envolvimento em trabalho ou carreira profissional, independência económica, estabelecimento de relações estáveis com o grupo de pares, desenvolvimento de relações de intimidade - nem sempre se verificam. São bem conhecidos e estudados (Haley, 1980) os fenómenos associados ao "leaving home", o qual pode ser bastante problemático, ganhando o formato do "living in home", ou então procedendo através do que Bowen (1978) designa por "cut off", ou seja, a ruptura emocional e/ou física entre as gerações. Uma independência física que não é acompanhada por autonomia emocional é uma pseudo-saída, podendo assumir diversas formas desde casamentos precipitados, gravidez fora do casamento, abuso do álcool, dependência de drogas, abandonos sucessivos de emprego/estudos ou despedimentos. Também podemos encontrar aqueles jovens adultos que ou tornam a voltar para casa, ou mantêm-se excessivamente dependentes (financeiramente, emocionalmente) dos pais e da família de origem em geral, desenvolvendo com elas relações excessivas de "lealdade" que põem em perigo projectos conjugais que possam ter.

Williamson (1981) defende que o desenvolvimento de relações adultas entre estas duas gerações só se poderá processar verdadeiramente quando terminar a fronteira hierárquica entre elas, o que passa por uma renegociação das estruturas de poder na direcção da igualdade. Este autor dá de tal modo importância a esta mudança que a considera como uma "nova" fase do ciclo de vida da família, referindo que a diferenciação mais completa da família de origem só se realizará perto da quarta década de vida, definindo, para tal, um conjunto de condições.

Com efeito, conseguir relacionar-se com os filhos como adultos, deixando as lentes da protecção e da orientação próprias dos pais, exige um esforço considerável de aceitação e respeito pelas diferenças mútuas de pensamento e comportamento. 


\section{Expansão de relações de modo a incluir noras/genros e netos}

Uma tarefa de desenvolvimento do casal de meia-idade consiste na modificação das relações no sistema familiar de modo a incluir genros, noras e netos. Vai ser necessária a aprendizagem de novos papéis - "ser sogros" e "ser avós".

Se bem que para algumas famílias se vá tornando progressivamente verdadeira a afirmação de que "não é um filho que sai da família, mas dois ou mais que entram para ela", este processo de expansão de relações nem sempre decorre assim tão linearmente. Depende de como foi sendo feita e aceite a saída dos filhos de casa e do processo do seu reconhecimento como adultos.

Para McGoldrick (1989), os problemas surgidos a propósito da escolha dos cônjuges dos filhos estão, frequentemente, relacionados com problemas não resolvidos das fases anteriores do ciclo de vida da família. Isto é bastante evidente quando a escolha conjugal é feita pelo jovem numa atitude desafiadora dos pais, podendo ser vivida como uma forma de rejeitar os valores considerados pela família como importantes.

As principais dificuldades que poderão surgir na relação com as novas famílias nucleares que se vão formando estão, com alguma frequência, relacionadas com excessiva interferência na vida privada dos filhos, mesmo que as intenções de ajuda e de apoio sejam as melhores. Também, por vezes, o casal de meia-idade sente inutilidade ao constatar que o jovem casal é auto-suficiente, ou sente-se indesejado, "a mais" nas relações. Algumas mães relacionam-se com as noras como se estas lhe tivessem ocupado o lugar. Há, também, casais que sentem os casamentos dos filhos com grande impacto pois, ao observarem o tipo de relação conjugal que eles vão desenvolvendo (com a necessária alteração de papéis sexuais), procedem a comparações com a própria relação conjugal (no passado e no presente). Por vezes, é difícil aceitar a periodicidade de visitas que os filhos fazem e adaptar-se a estilos diferentes de "ser e fazer família" - desde os que aparecem sem avisar e não gostam de ter dias previstos para se reunirem em família, até àqueles que só aparecem quando convidados ou em dias pré-fixados.

O nascimento dos netos - a quarta geração - vai originar, no sistema familiar, "subida" de gerações e novas relações de parentesco. Surgem netos e avós e, ainda, na maior parte das famílias, sobrinhos, tios e primos.

No que se refere à relação com os netos, caberá aqui destacar algumas representações do que é "ser avós", recolhidas por McCullough e Rutenberg (1989, p. 297):

- avós como figuras de autoridade que ajudam os pais na educação e socialização das crianças; 
- avós, especialmente se são mais jovens, que estão com os netos com o propósito fundamental de passarem um tempo divertido e agradável;

- avós como indicadores da continuidade intergeracional e, até, "árbitros" em questões entre gerações;

- avós como figuras importantes, conferindo significado ao passado pessoal dos mais novos; depositários das histórias de família.

Não pode ser omitida uma função importante que tem vindo a ser cada vez mais desempenhada pelos avós - a de ajuda dos pais em funções que lhes estariam atribuídas (por exemplo, ir buscar os netos à escola e dar-lhes assistência, nomeadamente nos trabalhos de casa); ou de "baby-sitting" à noite ou ao fim-de-semana. Nas relações avós-netos, assistimos a um "cativar recíproco": para os avós é o dom de uma "outra vida"; para os netos são relações de cumplicidade, magia e de descoberta com os avós.

Desenvolvimento de cuidados diversos à geração mais idosa e oportunidade de resolver desentendimentos entre gerações

Quando Zal (1992) se refere à geração da meia-idade como sendo a "geração sanduíche" pretende chamar a atenção para duas tarefas fundamentais do casal de meia-idade: trabalhar a independência progressiva dos filhos adolescentes e jovens adultos; e lidar com a dependência progressiva da geração mais idosa (os seus próprios pais).

Os acontecimentos de vida que, habitualmente, a geração mais idosa enfrenta são os seguintes: reforma, aumento de tempo disponível, segurança económica, diminuição do funcionamento físico, doenças diversas, morte do cônjuge, etc. Todos estes acontecimentos exigem um acompanhamento próximo, sobretudo, por parte da geração da meia-idade. É esperado (da parte das famílias, da sociedade e da cultura) que, principalmente as mulheres, cuidem física e emocionalmente dos seus pais e sogros, não só dando-lhes todo o tipo de apoio em casa deles ou, sendo caso disso, os levem para a sua casa ou, ainda, destinem sistemas de suporte adequados à situação, nomeadamente, internamento institucional. Dos homens de meia-idade é mais esperado o apoio afectivo, responsabilidades económicas e apoio na tomada de decisões respeitantes à vida dos familiares mais idosos. Sentir os pais envelhecer não só vai implicando uma inversão dos papéis até aí existentes, como gera a sensação de se estar "entregue a si próprio", de deixar de poder contar psicologicamente com os pais em momentos de crise.

O apoio à última geração traz, também, consigo, uma antevisão da velhice da geração de meia-idade - "somos a próxima geração, somos os próximos a estar na linha da frente". Isto torna-se ainda mais premente 
quando se enfrenta a morte de um dos pais e é necessário assumir o seu papel e algumas das suas responsabilidades, passando-se a ser a geração mais idosa do sistema familiar. Por vezes, a morte de um dos progenitores é seguida da coabitação com o outro que fica viúvo, o que vai exigir novos reajustamentos no sistema de relações familiares. É com relativa frequência que se desenvolvem ou acentuam desentendimentos com irmãos ou irmãs do casal de meia-idade que, face à necessidade de ajuda no apoio à geração mais idosa, não dão o contributo esperado.

Nesta fase do ciclo de vida, o casal de meia-idade consegue, com alguma frequência, um certo entendimento das diferentes problemáticas que se colocam às diferentes gerações. A sua posição de charneira entre elas, bem como uma certa experiência e sabedoria de vida, ajudam nesta tarefa de desenvolvimento, conseguindo-se, por vezes, resolver desentendimentos entre gerações. Passando por acontecimentos semelhantes aos que os seus pais já passaram, o casal de meia-idade percebe algumas das atitudes e comportamentos com que não tinha concordado anteriormente. Se virmos bem, trata-se de uns pais que também são filhos e de uns avós que também são pais. Poderíamos dizer que pode dar-se como que um certo "ajuste de contas" (resolução de velhas questões) entre as duas últimas gerações, aceitação e apreço, após o que se torna mais fácil e gratificante prosseguir a vida em conjunto.

\section{Estudos com casais portugueses}

Descritas as características gerais dos casais de meia-idade, bem como as respectivas tarefas evolutivas, é possível encontrar, apesar da diversidade dos casais, bem como da sua consequente singularidade - cada casal é único e irrepetível -, regularidades, ou seja, tipologias. Iremos ilustrar esta diversidade, em que também é possível encontrar regularidades, recorrendo a resultados de investigações com casais portugueses.

Num estudo, realizado com 422 adultos casados (214 do sexo feminino; 208 do sexo masculino) da zona da grande Lisboa, tivemos presentes as seguintes características sociodemográficas: tempo de casamento (30,8\% casados entre 2 a 5 anos; $29,9 \%$ entre 6 e 13 anos; $20,9 \%$ entre 14 e 24 anos; $18,5 \%$, com mais de 25 anos de casamento); número de filhos (23,5\% sem filhos; $29,1 \%$ com um filho; $28 \%$ com dois filhos; $19,3 \%$ com três ou mais filhos); escolaridade e estatuto ocupacional (Ribeiro, 2002).

Entre outros objectivos, pretendia-se adaptar para Portugal (Ribeiro, 2002) uma tipologia de relações com base num questionário de auto-avaliação - Escala de Dimensões Relacionais (EDR) - desenvolvido por Fitzpatrick (1988), que interpela os cônjuges em duas grandes áreas: os 
ideais pessoais para as relações (crença em papéis específicos e convencionais de género, valor da espontaneidade e da mudança); e a descrição do seu actual casamento (padrões de interdependência/autonomia e de resolução de conflitos). Os resultados, nestas dimensões, dos cônjuges, obtidos em separado, permitem calcular as definições relacionais, as quais combinadas permitem delinear quatro tipos de casais: tradicionais, independentes, ambivalentes e mistos ${ }^{6}$. Muito sinteticamente, os tradicionais têm valores convencionais sobre o casamento e a família, são muito interdependentes no casamento e discutem de boa vontade questões importantes; os independentes são mais liberais nos valores, são moderadamente interdependentes no seu casamento e estão habituados ao conflito; os ambivalentes oscilam relativamente aos valores familiares, não são muito interdependentes nos seus casamentos e tendem a evitar o conflito conjugal.

Quadro 1: Frequências dos Tipos Conjugais "Puros" e "Mistos"

\begin{tabular}{|c|c|c|c|c|}
\hline \multirow[b]{2}{*}{$\begin{array}{l}\text { Tipo conjugal } \\
\text { da mulher }\end{array}$} & \multicolumn{3}{|c|}{ Tipo conjugal do marido } & \multirow[b]{2}{*}{ Total } \\
\hline & Tradicional & Independente & Ambivalente & \\
\hline Tradicional & $\begin{array}{c}\boldsymbol{t} \boldsymbol{t} \quad 46 \\
(21,8 \%)\end{array}$ & $\begin{array}{cc}\boldsymbol{t} \boldsymbol{i} \quad 7 \\
(3,3 \%)\end{array}$ & $\begin{array}{lr}\text { ta } & 18 \\
(8,5 \%)\end{array}$ & 71 \\
\hline Independente & $\begin{array}{c}\text { it } \quad 4 \\
(1,9 \%)\end{array}$ & $\begin{array}{lr}\boldsymbol{i i} & 18 \\
(8,5 \%)\end{array}$ & $\begin{array}{l}\text { ia } 12 \\
(5,7 \%)\end{array}$ & 34 \\
\hline Ambivalente & $\begin{array}{c}a t \quad 25 \\
(11,8 \%)\end{array}$ & $\begin{array}{lr}a i & 10 \\
(4,7 \%)\end{array}$ & $\begin{array}{ll}a & a 8 \\
(32,2 \%)\end{array}$ & 103 \\
\hline Total & 75 & 35 & 98 & 208 \\
\hline
\end{tabular}

Dos 208 casais que constituíam a amostra portuguesa, e principiando pelos tipos conjugais puros, $21,8 \%$ eram tradicionais ( $t$ t), $32,2 \%$ revelaram-se ambivalentes ( $a a$ ) e, em percentagem reduzida, comparando com o estudo americano, 8,5\% eram independentes (ii). Dos tipos mistos predominaram aqueles em que um dos cônjuges era ambivalente (35 mulheres e 30 homens) - e, destes, era mais frequente a associação com um cônjuge tradicional (at ou ta) -, no caso de um dos cônjuges ser independente,

\footnotetext{
${ }^{6}$ Quando ambos os cônjuges partilham as mesmas crenças ideológicas, os mesmos níveis de interdependência e semelhantes abordagens ao conflito, são classificados como um dos tipos "puros" de casal (Tradicional, Independente, ou Ambivalente), quando não partilham constituem um dos seis tipos 'mistos' possíveis.
} 
predominou a respectiva associação com um cônjuge ambivalente e não tradicional.

Esta distribuição dos casais portugueses de acordo com a tipologia conjugal em estudo oferece-nos alguns comentários. Apesar da percentagem de tipos puros e mistos ser, no global, semelhante à encontrada noutros países (Fitzpatrick, 1988, 1993; Fitzpatrick \& Vangelisti, 1995), verificamos uma percentagem superior de cônjuges ambivalentes e inferior de cônjuges independentes (quer fazendo parte de tipos puros como de tipos mistos). Esta tendência verifica-se tanto para os maridos como para as mulheres, e poderá ser reveladora duma sociedade portuguesa em transformação, à procura de "novas formas de ser e estar casado", construindo modelos próprios de conjugalidade e de parentalidade. Para além disso, constatamos que o tipo misto mais frequente é o at (mulher ambivalente e marido tradicional), representando $11,8 \%$ da totalidade da amostra, o que pode ser indicador de uma sociedade portuguesa em mutação, na qual a alteração de papéis conjugais se faz sentir sobretudo nas mulheres.

Uma análise de qui-quadrado confirmou a relação com a variável 'tempo de casamento', $\chi^{2}(6,422)=13,78, p<0,05$ nas seguintes associações: há significativamente mais cônjuges tradicionais $(46,2 \%)$ e ambivalentes $(40,8 \%)$ do que independentes $(13,1 \%)$ casados entre 2 e 5 anos; nos casamentos de 6 a 13 anos também encontramos significativamente mais cônjuges tradicionais $(34,9 \%)$ e ambivalentes $(46,9 \%)$ do que independentes $(18,3 \%)$; nos casamentos de 14 a 24 anos encontramos significativamente mais cônjuges ambivalentes $(51,1 \%)$ do que independentes (17,05\%); nos cônjuges com 25 anos e mais de casamento, a percentagem de cônjuges ambivalentes $(58,9 \%$ ) é significativamente superior à dos cônjuges tradicionais $(21,8 \%)$ e independentes $(17,05 \%)$. Verifica-se, nesta amostra, que o número de cônjuges tradicionais diminui progressivamente, à medida que o tempo de casamento aumenta, que o número de cônjuges ambivalentes atinge o número máximo nos casamentos entre 6 e 13 anos, constituindo também o grupo mais frequente nos outros tempos de casamento. $\mathrm{O}$ número de cônjuges independentes mantém-se constante, não variando com o tempo de casamento.

Uma análise de variância multivariada (MANOVA), tendo como variável independente o 'tempo de casamento' (com quatro níveis) e os valores médios obtidos nas oito subescalas da EDR como variáveis dependentes, confirmou o efeito geral significativo da variável tempo de casamento $[\mathrm{F}(24,1192)=5,14, \mathrm{p}<0,00001$, Wilks' lambda $=0,75]$. Os efeitos univariados foram examinados com ANOVA, seguida de comparações post hoc pelo teste Tuckey HSD para grupos com frequências diferentes, conforme o Quadro 2. 
Verificamos que os resultados médios mais elevados das subescalas de ideologia (tanto do Tradicionalismo como da Incerteza e Mudança e de Evitamento do Conflito) são obtidos pelos cônjuges casados há mais anos (grupo 4) distinguindo-se significativamente dos outros grupos, evidenciando o maior relevo que é dado, nos casamentos de maior duração, a estas dimensões. Estes resultados poderão significar uma maior percepção, por parte dos casamentos de maior duração, de que as crenças, padrões e valores que os cônjuges têm relativamente à sua relação e à família (paradigma familiar) são importantes enquanto determinantes das interacções. O facto de serem também os casais com 25 ou mais anos de casamento a valorizar mais o evitamento do conflito poderá ser indicador de um maior conhecimento e aceitação da relação conjugal, típico da fase do ciclo de vida em que se encontram.

Quadro 2: Médias, DP e ANOVA dos grupos por tempo de casamento

\begin{tabular}{|c|c|c|c|c|c|}
\hline \multirow[b]{2}{*}{$\begin{array}{l}\text { Subescalas } \\
\text { EDR }\end{array}$} & \multicolumn{5}{|c|}{ Tempo de casamento } \\
\hline & $\begin{array}{c}1 \\
(\mathrm{n}=130)\end{array}$ & $\begin{array}{c}2 \\
(\mathrm{n}=126)\end{array}$ & $\begin{array}{c}3 \\
(\mathrm{n}=88)\end{array}$ & $\begin{array}{c}4 \\
(n=78)\end{array}$ & $\mathrm{F}(3,418)$ \\
\hline Tradicionalismo & $\begin{array}{l}5,21 \mathrm{a} \\
(0,71)\end{array}$ & $\begin{array}{l}5,22 b \\
(0,81)\end{array}$ & $\begin{array}{l}5,32 \mathrm{c} \\
(0,76)\end{array}$ & $\begin{array}{c}\mathbf{5 , 6 5 a b c} \\
(0,76)\end{array}$ & $6,6^{* * *}$ \\
\hline $\begin{array}{l}\text { Incerteza e } \\
\text { Mudança }\end{array}$ & $\begin{array}{l}4,26 \mathrm{a} \\
(0,84)\end{array}$ & $\begin{array}{l}4,20 \mathrm{bc} \\
(0,99)\end{array}$ & $\begin{array}{l}4,61 \mathrm{c} \\
(1,04)\end{array}$ & $\begin{array}{c}\mathbf{4 , 7 1} \mathbf{a b} \\
(0,93)\end{array}$ & $7,0 * * *$ \\
\hline Partilha & $\begin{array}{c}\mathbf{5 , 4 0 a b c} \\
(0,61)\end{array}$ & $\begin{array}{l}5,11 \mathrm{ad} \\
(0,66)\end{array}$ & $\begin{array}{l}4,86 \mathrm{~b} \\
(0,78)\end{array}$ & $\begin{array}{l}4,78 \mathrm{~cd} \\
(0,77)\end{array}$ & $17,1 * * *$ \\
\hline Autonomia & $\begin{array}{c}3,07 \\
(0,96)\end{array}$ & $\begin{array}{c}3,06 \\
(0,96)\end{array}$ & $\begin{array}{c}3,16 \\
(1,14)\end{array}$ & $\begin{array}{c}3,18 \\
(1,08)\end{array}$ & $0,33 \mathrm{~ns}$ \\
\hline $\begin{array}{l}\text { Espaço } \\
\text { indiferenciado }\end{array}$ & $\begin{array}{c}\mathbf{5 , 1 0 a b} \\
(0,76)\end{array}$ & $\begin{array}{c}4,85 \\
(0,81)\end{array}$ & $\begin{array}{l}4,74 a \\
(0,85)\end{array}$ & $\begin{array}{l}4,69 b \\
(0,95)\end{array}$ & $5,4 * *$ \\
\hline $\begin{array}{l}\text { Regularidade } \\
\text { temporal }\end{array}$ & $\begin{array}{c}5,35 \\
(0,89)\end{array}$ & $\begin{array}{c}5,39 \\
(1,12)\end{array}$ & $\begin{array}{c}5,40 \\
(0,93)\end{array}$ & $\begin{array}{c}5,42 \\
(1,01)\end{array}$ & $0,09 \mathrm{~ns}$ \\
\hline $\begin{array}{l}\text { Evitamento do } \\
\text { conflito }\end{array}$ & $\begin{array}{r}2,62 \mathrm{ab} \\
(0,78)\end{array}$ & $\begin{array}{l}2,77 \mathrm{c} \\
(0,79)\end{array}$ & $\begin{array}{l}2,98 \mathrm{a} \\
(0,94)\end{array}$ & $\begin{array}{c}\mathbf{3 , 2 4 b c} \\
(0,78)\end{array}$ & $10,4 * * *$ \\
\hline Assertividade & $\begin{array}{c}2,25 \\
(0,67)\end{array}$ & $\begin{array}{c}2,36 \\
(0,77)\end{array}$ & $\begin{array}{c}2,23 \\
(0,73)\end{array}$ & $\begin{array}{c}2,37 \\
(0,71)\end{array}$ & $1,1 \mathrm{~ns}$ \\
\hline
\end{tabular}

Por outro lado, o grupo dos cônjuges do grupo 1 (2-5 anos de casamento) obtiveram resultados significativamente superiores aos obtidos pelos outros grupos nas subescalas de Partilha e de Espaço Indiferenciado, 
o que é consonante com a fase inicial do ciclo de vida de um casal, em que existe maior fusão entre os cônjuges. Não se registaram diferenças significativas entre os grupos, nos resultados das subescalas de Autonomia, Regularidade Temporal e Assertividade.

Este estudo, essencialmente quantitativo no início, foi continuado através de estudos de caso em que o método principal foi a entrevista semiestruturada ao casal (Ribeiro, 2002). De todos os estudos de caso realizados, seleccionámos os respeitantes aos casais de meia-idade e, destes, três que fossem ilustrativos de cada um dos tipos conjugais encontrados - tradicional, independente e ambivalente -, procurando documentar a singularidade dentro da regularidade conjugal a que nos referimos anteriormente. Para tal, iremos recorrer a alguns excertos das entrevistas.

\section{Tradicional}

Trata-se de um casal composto por M (48 anos) e por $\mathrm{H}$ (47 anos) ${ }^{7}$, casados há 21 anos, com três filhos (duas raparigas com 20 e 18 anos, respectivamente e um rapaz com 15 anos). Ambos trabalham, são arquitectos, $\mathrm{M}$ por conta de outrém e $\mathrm{H}$ por conta própria.

No que se refere aos diferentes papéis, dão muito relevo aos do subsistema parental (e.g., M - "Os filhos são a nossa vida, por isso gostamos muito de estar com eles, passar férias sempre com eles, aliás, as fotografias de que mais gosto são aquelas em que estamos os cinco. Nunca imaginei que não ia ter filhos"; H - "Nós sabemos que os filhos não são nossos, estão à nossa guarda, mas fazem parte de nós. $\mathrm{Eu}$, se não tivesse filhos, adoptava. Aliás, já tivemos várias vezes essa conversa, senão, estávamos agora em situação de adoptar, do próximo não ser filho directo, mas adoptado. Mas o que eu sinto em relação a ser pai é 'Toma lá, está aqui, és responsável por ele"').

Um diferendo está relacionado com a gestão dos diferentes papéis: $\mathrm{H}$ - "Eu gostava que ela não trabalhasse tanto fora de casa e voltássemos aos papéis antigos do homem e da mulher"; $\mathrm{M}$ - "Eu, de forma nenhuma, ia conseguir estar em casa a fazer só isso, embora pense que a coisa mais importante são os filhos, mas não consigo".

Consideram que já existiram momentos de crise, mas que isso nunca pôs, nem porá em causa a relação (e.g., M - "Já tivemos uma situação de crise valente, exactamente porque eu sentia que não me conseguia cruzar com ele, por causa do tempo. Não conseguíamos, mesmo fisicamente, não nos encontrávamos. Eu tinha medo que acontecesse dar demasiado aos

\footnotetext{
${ }^{7}$ Optamos por designar as referências aos membros dos casais entrevistados por $\mathrm{M}$ quando se referem às mulheres, e por $\mathrm{H}$ quando se referem aos maridos.
} 
outros e já não ter nada para dar a nós, não é que eu sentisse que ele estava esgotado, eu tinha medo em relação aos miúdos... quando dei esse sinal era para prevenir").

As crenças de género é uma área onde não existe grande acordo. Apesar de terem, ambos, profissões às quais dedicam bastante tempo por considerarem importantes e de dividirem os papéis familiares, enquanto $\mathrm{M}$ considera não existir especificidade de papéis em função de se 'ser homem ou mulher' (e afirma ter prova disso no próprio caso deles), $\mathrm{H}$ considera o contrário: "Não é preciso deixar de ter profissão, mas acho que a mãe como mãe, como mulher, é chamada por todas as razões, até físicas e relacionais, não tenho dúvida nenhuma sobre isso, a fazer esse papel. Não estou a dizer que não haja pais que não o possam fazer. Os filhos naturalmente podem receber das mães coisas que dos pais não... não fui eu que andei 9 meses com eles na barriga, não sou eu que tenho uma ligação fisica a eles...".

Quanto à ideologia conjugal, têm pressupostos muito claros e definidos (e.g., H - "Casar, significa comprometer-se seriamente. A partir do momento que dizemos "Sim, eu quero", tudo o resto é em crescendo, ou seja, completamo-nos cada vez melhor um ao outro, os nossos defeitos passam a fazer parte, embora tentemos ajustá-los e, as qualidades a serem exponenciadas. A partir do momento em que casamos pela Igreja, há uma coisa que pomos acima de tudo, que é a nossa ligação. Fizemos um compromisso que está feito e assumido, e é responsável e passa a estar acima de nós. Ou seja, não o posso quebrar, tenho é que o construir cada vez mais e, a partir daí, passa a ser referência para tudo. Está acima do meu gosto, da minha emoção, de qualquer tentação, não o posso pôr em causa. Se não posso pôr em causa, liberta-me de tudo para poder fazer outras coisas".

\section{Independente}

O casal de meia-idade que ilustra a definição da relação conjugal como independente é composto por $\mathrm{M}$, de 45 anos, está casada há 25 anos com $\mathrm{H}$ de 49 anos e têm um filho com 24 anos. M é directora financeira de uma empresa e H é professor do Ensino Secundário.

Relativamente aos diferentes papéis, $\mathrm{M}$ e $\mathrm{H}$ consideram que estabeleceram prioridades diferentes, mesmo opostas, no que se refere à família e ao trabalho. Enquanto $\mathrm{M}$ afirma "sempre liguei muito à profissão, hoje questiono isso. A minha independência passa pela independência económica. Sempre tive muitos objectivos profissionais, é um gosto, agora queria mudar e não consigo. Quando tenho tempo para pensar, questiono o tempo que temos para estar juntos e, às vezes, faço tentativas de mudança, só que depois vou para o trabalho e aquilo absorve-me e esqueço-me que 
eu própria pensei dar mais atenção a mim, à família, e já chego a casa mais cansada e, pronto, volto ao mesmo. Reconheço que há colegas homens que me deslumbram profissionalmente", o H contrapõe "nunca tive grandes objectivos de carreira profissional, tenho mais disponibilidade para tudo, dedico-me a ela e a tentar desviá-la da profissão".

Para M, o papel mais difícil é o parental (e.g., "para mim ser profissional é fácil, até manter uma relação conjugal e fácil, é só preciso ser tolerante, agora educar é muito difícil. Há grande cumplicidade entre nós, mas agora que eu começo a perceber que o nosso filho vai partir, reaproximei-me do meu marido. O nosso filho é muito partilhado, mas houve fases em que o pai teve muito a incumbência de o acompanhar, tinha muito mais tempo do que eu. Era o encarregado de educação e ele é que é professor e estudou muito com ele".

Em relação ao poder, $\mathrm{H}$ esclarece: "somos bastante democráticos, nem um nem outro somos possessivos nem materialistas, não temos espírito de posse, excepto para o filho".

M acrescenta: "Ele gosta de motas e de livros, eu gosto de roupas e respeitamos o gosto um do outro; ele janta com os amigos dele e eu vou jantar com os meus; se for almoçar com um amigo, ele não vê mal nenhum nisso, sabe perfeitamente que é um amigo, se for mais alguma coisa ele também sabe".

Consideram, ambos, que só se casaram, em vez de se juntarem, por causa das famílias tradicionais a que pertenciam, a quem não queriam dar um desgosto: "hoje era capaz de não me casar" (M); "nunca fui muito ligado ao casamento, porque não foi o casamento que nos ligou, já nos dávamos bem" $(\mathrm{H})$.

Ainda relativamente à ideologia conjugal, realçam, ambos, como mais importante na relação conjugal, "deixar que cada um tenha o seu espaço e muita calma na resolução das dificuldades". M destaca, ainda, a tolerância e o respeito pela pessoa um do outro - "não tentar mudar nada no outro porque impor mudanças não resulta" - bem como a confiança.

\section{Ambivalente}

Por último, o casal de meia-idade que constitui o estudo de caso ilustrativo do tipo ambivalente é composto por $\mathrm{M}$ e $\mathrm{H}$, de 56 e 54 anos respectivamente, estão casados há 28 anos, têm dois filhos e dois netos. São ambos licenciados pelo Instituto Superior Técnico, sendo M professora e $\mathrm{H}$ engenheiro.

É diferente a importância conferida por $\mathrm{M}$ e $\mathrm{H}$ aos diversos papéis familiares e profissionais. Para $\mathrm{H}$ "o aspecto profissional pesou muito porque, por diversas razões, tenho sido chamado a desempenhar cargos com 
alguma importância e relevância e, isso, tira-me muito tempo". M concorda: "Ele é um profissional activo, mas, caseiramente, é muito pouco criativo, muito pouco activo na vivência da casa, só quer ler o jornal. Eu gosto da minha profissão, já me dou ao luxo de poder escolher o horário, que é de manhã, como professora de informática, e costumam dizer que sou conciliadora, que consigo ver sempre as duas partes. Realizo-me profissionalmente de manhã e, depois, não há dúvida que dou muito mais realce à vida de família, dá-me imenso prazer fazer pratos novos, mimos à rapaziada, aos netos e aos meus pais, a quem prestamos muito apoio... não há dúvida, eu sou o pilar mais forte da parte da família e isso dá-me muita satisfação".

Apesar de trabalharem os dois, consideram existir, na sua família, uma divisão tradicional dos papéis, mas, conforme refere M, "não é por ser mulher que eu tenho que ir fazer as coisas", ou H, "não tem a ver com ser área de homem ou de mulher, tem a ver com as características de cada um".

$\mathrm{H}$ opina, em contradição com o que tinha defendido anteriormente, que as diferenças entre género feminino e masculino tenderão a esbater-se: "o que não traz vantagem para a sociedade, porque há determinados tipos de função que são masculinos e outros femininos. Um mundo comandado por mulheres não é aquele mundo em que eu gostaria de viver... há mais mulheres juizas e veja o que é a decisão de uma mulher juíza quando está no período de tensão pré-menstrual em relação à decisão que ela terá 15 dias depois". Contrariamente, M considera que as diferenças vão existir sempre "porque a química diferente que há em nós vai sempre existir".

No que se refere à intimidade e compromisso na relação, $M$ utiliza diversas palavras para chegar ao significado de intimidade: "cumplicidade, ternura, conhecer da pessoa aquilo que não se vê (o significado do olhar), tocar, encostar, estar junto, sexualidade, saber respeitar o espaço do outro". Para H, intimidade é "tudo, desde que estejamos ao pé um do outro, por exemplo, saber a frase que o outro vai dizer" e, também, "a existência de um espaço só nosso". Casar significou "que não queríamos entrar em conflito com os nossos pais e não tem nada a ver com compromisso" (H). E: "eu também era capaz de assumir uma vivência em comum sem ser o casamento... mas, se o meu outro filho for viver junto, eu sinto um certo desconsolo, mas é disparate. $O$ que há a preservar é o aspecto legal e pensar no futuro" (M).

\section{Conclusão}

A vida das pessoas de meia-idade, homens ou mulheres, pode ser muitíssimo enriquecedora e gratificante. É uma fase em que é possível 
viver com menos stress, dando um mais justo peso ao impacto dos acontecimentos de vida, gozando já alguns frutos do trabalho e do esforço de anos anteriores. Tudo depende do alcance bem-sucedido ou não das tarefas evolutivas (mais pessoais) enunciadas e daquelas que se colocam ao casal, enquanto casal que se mantém ao longo do ciclo de vida familiar, e que tivemos oportunidade de analisar e reflectir relativamente às diversas formas que pode assumir - tradicional, independente, ambivalente.

É precisamente porque cada geração tem costumes e padrões específicos, valores e tradições muito próprios, que se verificam encontros e desencontros de gerações. E estes encontros e desencontros de gerações, se bem que desgastantes (e, por vezes, radicais), resultam, muitas vezes, em enriquecimento mútuo de relações. Basta constatarmos que qualquer criança se desenvolve não só no mundo dos seus pais e dos da sua geração, mas também na rede mais alargada dos seus avós e da história dos seus antepassados. É em toda uma cultura de família com segredos, histórias e rituais muito próprios que cada um de nós se desenvolve. Portanto, há uma relação natural entre as gerações, baseada na biologia, verificável psicológica e culturalmente e experimentada sentimentalmente através das ligações afectivas. Uma característica interessante da relação entre gerações consiste nos seus constantes movimentos ambivalentes: tanto encontramos comflitos - o tão falado choque de gerações -, como nos deparamos com uma profunda e natural atracção entre as gerações. Os conflitos são quase inevitáveis entre os mais idosos - convencidos da verdade da sua experiência de vida, da certeza das suas opções, dos valores de segurança e estabilidade e os mais novos, desejosos de inovar, ousados e independentes. Mas a atracção é, também, natural, porque os mais novos sabem que é aos mais velhos que vão buscar as suas raízes e os mais velhos sabem que os mais novos é que os vão continuar. Sabem que são parte uns dos outros.

É o permanente movimento do "dar e receber" que constitui a riqueza intergeracional da família. Para que os encontros sejam mais frequentes que os desencontros é importante que a geração mais nova compreenda que a mais velha pretende ajudar e não impor e que os mais velhos se apresentem não como modelos obrigatórios, mas como alguém com quem se pode interagir em liberdade.

Trata-se de, integrando as características actuais dos casais de meia-idade anteriormente descritas e percebendo a sua diversidade, designadamente na tipologia tradicional, ambivalente e independente, intervir (preventiva e clinicamente) numa perspectiva de resiliência familiar (Walsh, 2003). Por outras palavras, a proposta vai no sentido de enfatizar não os défices familiares, mas os respectivos desafios, com a convicção no potencial de reestruturação das famílias, promovendo o reforço das competências conjugais e fortalecendo os laços familiares. 
Citando o psiquiatra Zal (1992, p. 207), "aquilo que se modifica com a meia-idade não é o que sabemos (conhecimentos) realmente, mas sim as pequenas diferenças e nuances que dão às coisas um novo significado. $\mathrm{O}$ que se altera é a perspectiva. Atinge-se a capacidade para se ter uma visão de conjunto. Torna-se mais claro aquilo que realmente importa na vida...".

\section{Referências}

Bahr, S. (Ed.) (1992). Family research. Nova Iorque: Lexington Books.

Belsky, J. (1990). Children and marriage. In F. D. Fincham \& T. N. Bradbury (Eds.), The psychology of marriage: Basic issues and applications (pp. 172-200). Nova Iorque: The Guilford Press.

Bowen, M. (1978). Family therapy in clinical practice. New York: Jason Aronson.

Caillé, P. (1991). Un et un font trois - le couple révelé à lui-même. Paris: ESF.

Carter, E., \& McGoldrick, M. (1989). Overview: The changing family life cycle - A framework for family therapy. In E. Carter \& M. McGoldrick (Eds.), The changing family life cycle - A framework for family therapy (2 Ed., pp. 3-29). Boston: Allyn and Bacon.

Dickson, F. (1997). Aging and marriage: Understanding the long-term, later-life marriage. In W. K. Halford \& H. J. Markman (Eds.), Clinical handbook of marriage and couples intervention (pp. 255-269). England: Wiley.

Duvall, E.(1977). Marriage and family development (5 ${ }^{\mathrm{a}} \mathrm{Ed}$.). Nova Iorque: Lippincott Company.

Erikson, E. (1968). Identity: Youth, and crisis. Nova Iorque: Norton.

Feeney, J. A., Noller, P., \& Ward, C. (1997). Marital satisfaction and spousal interaction. In R. Sternberg \& M. Hojjat (Eds.), Satisfaction in close relationships (pp. 160-189). Nova Iorque: The Guilford Press.

Fisher, H. (1992). Anatomy of love - A natural history of adultery, monoghamy and divorce. Reino Unido: Simon \& Schuster.

Fitzpatrick, M. A. (1988). Between husbands and wives - Communication in marriage. California: Sage Publications.

Fitzpatrick, M. A., Fey, J., Segrin, C., \& Schiff, J. L. (1993). Internal working models of relationships and marital communication. Journal of Language and Social Psychology, 12 (1/2), 103-131.

Fitzpatrick, M. A., \& Vangelisti, A. L. (1995). Explaining family interactions. London: Sage Publications.

Fletcher, G. (2002). The new science of intimate relationships. Oxford: Blackwell Publisher.

Fletcher, G., \& Thomas, G. (2000). Behavior and on-line cognition in marital interaction: A longitudinal study. Personal Relationships, 7, 111-130.

Glenn, N. D. (1990). Quantitative research on marital quality in the 1980s: A critical review. Journal of Marriage and the Family, 52, 818-83. 
Glenn, N. D. (1998). The course of marital success and failure in five American 10-year marriage cohorts. Journal of Marriage and the Family, 60, 569-576.

Haley, J. (1980). Leaving Home - The therapy of disturbed young people. Nova Iorque: Mc Graw-Hill.

Heaton, T. B. (1991). Time-related determinants of marital dissolution. Journal of Marriage and the Family, 53, 285-295.

Hiller, D., \& Philliber, W. (1988). "The divison of labor in contemporary marriage: Expectations, perceptions, and performance". In A. Skolnick \& J. Skolnick (Eds.), Family in transition. Boston: Scott, Foresman and Company.

Instituto Nacional de Estatística de Portugal (2002a). A nupcialidade em Portugal: resultados definitivos, 2001, retirado da Internet em http://www.ine.pt.

Instituto Nacional de Estatística de Portugal (2002b). A divorcialidade em Portugal: resultados definitivos, 2001, retirado da Internet em http://www.ine.pt.

Karney, B. R., \& Bradbury, T. N. (1995). The longitudinal course of marital quality and stability: A review of theory, method, and research. Psychological Bulletin, 118, 3-34.

Lauer, R., \& Lauer, J. (1986). Factors in long-term marriages. Journal of Family Issues, 7, 382-390.

Levenson, R., Carstensen, L., \& Gottman, J. (1994). The influence of age and gender on affect, physiology, and their interrelations: A study of long-term marriages. Journal of Personality and Social Psychology, 67 (1), 56-68.

Lindahl, K. M., Malik, M., \& Bradbury, T. N. (1997). The developmental course of couples'relationships. In W. K. Halford \& H. J. Markman (Eds.), Clinical handbook of marriage and couples intervention (pp. 203-223). Reino Unido: Wiley.

Minuchin, S. (1974). Families and family therapy. Londres: Tavistock.

McCullough, P., \& Rutenberg, S. (1989). Launching children and moving on. In E. Carter \& M. McGoldrick (Eds.), The changing family life cycle - A framework

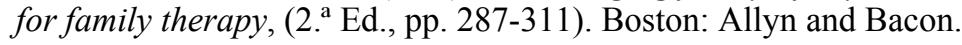

McGoldrick, M. (1989). The joining of families through marriage: The new couple. In E. Carter \& M. McGoldrick (Eds.), The changing family life cycle - A

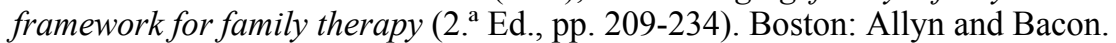

Narciso, I. (2001). Conjugalidades satisfeitas mas não perfeitas: À procura do padrão que liga. Tese de Doutoramento não publicada. Lisboa: Faculdade de Psicologia e de Ciências da Educação da Universidade de Lisboa.

Orbuch, T. L., House, J. S., Mero, R. P., \& Webster, P. S. (1996). Marital quality over the life course. Social Psychology Quaterly, 59 (2), 162-171.

Pina Prata, F. X. (1994). Formas de intervenção da terapia familiar e diagnóstico sistémico psicoterapêutico: Complexidade e turbulência. In H. Marchand \& H. R. Pinto (Eds.), Actas do colóquio Família - Contributos da psicologia e das ciências da educação (pp. 201-228). Lisboa: Educa / Faculdade de Psicologia e de Ciências da Educação da Universidade de Lisboa.

Pitman, J., \& Lloyd, S. (1988). Quality of family life, social support, and stress. Journal of Marriage and the Family, 50, 53-67. 
Relvas, A. P. (1996). O ciclo vital da família - Perspectiva sistémica. Porto: Edições Afrontamento.

Ribeiro, M. T. (1991). Transições de fase no ciclo de vida da famíla - Uma investigação com famílias portuguesas. Provas de Aptidão Pedagógica e de Capacidade Científica não publicadas. Lisboa: Universidade de Lisboa.

Ribeiro, M. T. (1996). El nido vacío. In M. Millan (Ed.), Psicologia de la familia Un enfoque evolutivo y sistémico (pp. 133-152). Valencia: Promolibro.

Ribeiro, M. T., \& Costa, M. E. (2002). Estilos de vinculação, orientação de papéis sexuais, sexo e satisfação conjugal: Um estudo com casais portugueses. Revista de Consulta Psicológica da Universidade do Porto.

Ribeiro, M. T. (2002). Da diversidade do feminino e do masculino à singularidade do casal. Tese de Doutoramento não publicada. Lisboa: Faculdade de Psicologia e de Ciências da Educação da Universidade de Lisboa.

Sanders, M. R., Nicholson, J. J., \& Floyd, F. (1997). Couples'relationships and children. In W. K. Halford \& H. J. Markman (Eds.), Clinical handbook of marriage and couples intervention (pp. 225-253). Reino Unido: Wiley.

Steil, J. M. (1997). Marital equality - Its relationship to the well-being of husbands and wives. Londres: Sage Publications.

Stierlin, H. (1979). Separating parents and adolescents: A perspective on running away, schizophrenia and waywardness. Nova Iorque: Quadrangle.

Suitor, J. J. (1991). Marital quality and satisfaction with the divison of household labor across the family life cycle. Journal of Marriage and the Family, 53, 221-230.

Swensen, C., Eskew, R., \& Kohlepp, K. (1981). Stage of family life cycle, ego development, and the marriage relationship. Journal of Marriage and the Family, 43 (4), 841-853.

Thomas, G., Fletcher, G., \& Lange, C. (1997). On-line empathic accuracy in marital interaction. Journal of Personality and Social Psychology, 76, 72-89.

Townsend, J., \& Carbone, C. (1980). Menopausal syndrome: Illness or Social Role A transcultural analysis. Cultural Medicine and Psychiatry, 4, 229-248.

Vaillant, C. O., \& Vaillant, G. E. (1993). Is the U-curve of marital satisfaction an illusion? A 40-year study of marriage. Journal of Marriage and the Family, 55, 230-239.

Walsh, F. (2003). Family resilience: A framework for clinical practice. Family Process, 42, 1-18.

Williamson, D. (1981). Personal authority via termination of the intergenerational hierarchical boundary: A "new" stage in the family cycle. Journal of Marital and Family Therapy, 7, 441-452.

Zal, H. M. (1992). A Geração Sanduíche-Entre filhos adolescentes e pais idosos. (tradução portuguesa em 1993). Lisboa: Difusão Cultural.

Zuo, J. (1992). The reciprocal relationship between marital interaction and marital hapiness: A three-wave study. Journal of Marriage and the Family, 54, 870-878 . 